CLINICAL STUDY

\title{
A novel HESX1 splice mutation causes isolated GH deficiency by interfering with mRNA processing
}

\author{
Daniela Vivenza, Michela Godi ${ }^{1}$, Maria Felicia Faienza ${ }^{2}$, Simona Mellone ${ }^{1}$, Stefania Moia ${ }^{3}$, Anna Rapa ${ }^{3}$, \\ Antonella Petri ${ }^{3}$, Simonetta Bellone ${ }^{3}$, Stefania Riccomagno ${ }^{3}$, Luciano Cavallo ${ }^{2}$, Mara Giordano ${ }^{1, *}$ \\ and Gianni Bona ${ }^{3, *}$ \\ Laboratorio di Oncologia Ospedale Santa Croce e Carle, 12100 Cuneo, Italy, ${ }^{1}$ Laboratorio di Genetica Umana, Dipartimento di Scienze Mediche, Università \\ del Piemonte Orientale, Via Solaroli 17, 28100 Novara, Italy, ${ }^{2}$ Dipartimento di Biomedicina dell'Età Evolutiva, Università degli Studi di Bari, 70100 Bari, \\ Italy and ${ }^{3}$ Clinica Pediatrica, Ospedale Maggiore di Novara e Dipartimento di Scienze Mediche, Università del Piemonte Orientale, 28100 Novara, Italy \\ (Correspondence should be addressed to M Giordano; Email: giordano@med.unipmn.it)
}

*(M Giordano and G Bona are joint senior authors)

\begin{abstract}
Objective: Mutations in HESX1 represent a rare cause of GH deficiency (GHD) associated with a broad spectrum of other anomalies. We searched for causative mutations in a cohort of 244 Italian patients affected by combined and isolated GHD (IGHD).

Methods: The HESX1 gene-coding region and exon-intron boundaries were screened by denaturing HPLC scanning.

Results: A novel mutation adjacent to the invariant donor splice site of intron 2 (c. $357+3 \mathrm{G}>\mathrm{A}$ ) was identified at the heterozygous state in an IGHD patient. The in vitro and in vivo mRNA analysis of the wild-type HESX1 allele revealed the presence of the whole cDNA and two isoforms lacking exon 2 and exons 2-3 respectively. The mutant HESX1 allele yielded only two splicing products, the whole cDNA and the cDNA missing exons 2-3, whereas the mRNA lacking exon 2 was absent. An in vitro assay demonstrated that the exon 2-deleted mRNA, predicting a prematurely truncated protein, is subjected to nonsense-mediated mRNA decay (NMD).

Conclusions: The c.357+3G>A mutation prevents the generation of one of the alternative isoforms normally produced by the wild-type allele, predicting a truncated HESX1 protein. The mutation is likely to cause IGHD in the heterozygous patient by interfering with the downregulation of HESX1 expression mediated by alternative splicing and NMD.

Our results open new insight into the mechanism of HESX1 regulation suggesting that the coupling of alternative splicing and NMD might play a fundamental role in directing the HESX1 expression, and that the alteration of this process might lead to severe consequences.
\end{abstract}

European Journal of Endocrinology 164 705-713

\section{Introduction}

The anterior pituitary gland is composed of five cell types secreting six hormones: GH secreted by somatotrophs; prolactin (PRL) secreted by lactotrophs; FSH and LH secreted by gonadotrophs; TSH secreted by thyrotrophs; and ACTH secreted by corticotrophs. These highly differentiated cells arise during embryogenesis in a distinct spatial and temporal fashion from a layer of oral ectoderm termed the Rathke's pouch (1) through a cascade of signaling molecules and a large number of transcription factors (2). This is a coordinated process mediated by the sequential expression of specific genes and their subsequent attenuation at critical stages of the pituitary development. Genes that are expressed early in pituitary embryogenesis are implicated in organ commitment but are also involved in the repression and activation of downstream target genes that have specific roles in directing the cells toward a particular fate. Over the last decade, naturally occurring mutations in these developmental genes, such as HESX1, PROP1, POU1F1, LHX3, LHX4, SOX2, and SOX 3 have led to significant insights into pituitary disorders in humans and, the homologous genes, in mouse (3), ranging in severity from central nervous system (CNS) anomalies with no pituitary function to milder forms in which one or more of the pituitary hormones are absent, namely isolated GH deficiency (IGHD) and combined pituitary hormone deficiency (CPHD) (4).

The paired-like homeobox gene, Hesx 1 (homeobox expressed in embryonic stem cells) is one of the earliest markers of the pituitary development $(3,5-7)$. Hes $x 1$ is mainly expressed in the developing forebrain and the Rathke's pouch at mouse embryonic stage (e) 9.5 and is maintained until (e)12.5, after which it is rapidly 
extinguished. Extinction of Hes $x 1$ is important for activation of downstream genes such as Prop1, suggesting that they act as opposing transcription factors. Premature expression of Prop 1 can block pituitary organogenesis, whereas prolonged expression of Hes $x 1$ can block Prop1-dependent activation (8).

Hes $x 1$ shows a typical highly conserved 60 amino acids structural motif, the homeodomain (HD), which can bind DNA in a sequence-specific manner (9) and a basic repressive domain at the $\mathrm{N}$-terminus (the engrailed homology domain, eh1) characterized by seven amino acidic residues (amino acids 21-27) (10). Both the functional domains of Hes $x 1$ are involved in the repressive action by recruitment of the nuclear receptor co-repressor (NCOR) and by another co-repressor, the transducin-like enhancer of split 1 (TLE1) at the HD and at the repressive domain respectively $(9,11,12)$.

Null mutant mice for Hes $x 1$ display a phenotype characterized by anophthalmia or microphthalmia and midline neurological defects (e.g. absent septum pellucidum and pituitary hypoplasia), reminiscent of a rare human syndrome, the septo-optic dysplasia (SOD). This condition is characterized by hypopituitarism, pituitary hypoplasia, optic nerve hypoplasia, and abnormalities of midline brain structures (13) with only $30 \%$ of patients manifesting all the associated anomalies (14). Given the similarities between the murine Hes $x 1$ null mutant phenotype and SOD, the role of the human homolog of this gene was investigated in patients with SOD and milder pituitary phenotypes (3).

Initially, a homozygous missense mutation (R160C) (3) within the homeobox domain of HESX1 was detected in two siblings born to consanguineous parents with SOD, agenesis of the corpus callosum, optic nerve hypoplasia, a hypoplastic anterior pituitary gland and complete panhypopituitarism (15).

To date, 13 mutations in the HESX1 gene have been reported in a broad spectrum of phenotypes ranging from IGHD to CPHD associated in some cases with anomalies such as SOD, pituitary malformations, like ectopy of the neurohypophysis or pituitary aplasia (16-22). Mutations in HESX1 may be present both at the homozygous $(n=3)$ and at the heterozygous states $(n=10)$. The patients carrying mutations at the heterozygous state generally show a milder phenotype than the homozygous patients. Whereas the condition in homozygous subjects displays full penetrance, the heterozygous HESX1 mutations are invariably associated with reduced penetrance. Consequently, most of the patients are sporadic as their carrier relatives are frequently unaffected.

In this study, we screened the HESX1 gene in a large group of patients, most of whom were sporadic, affected by either IGHD or CPHD associated with or without anomalies of the brain.

A novel mutation adjacent to the invariant donor splice site of intron $2(c .357+3 G>A)$ was identified at the heterozygous state in an IGHD patient. To assess the functional consequences of this variation, the transcripts generated by the normal and the mutant alleles were analysed.

\section{Subjects and methods}

\section{Subjects}

A total of 244 Italian patients (156 males and 88 females) with pituitary hormone deficiency were recruited from 1999 to 2009 from different centers of the country.

Of the 244 Italian patients, four (two IGHD and two CPHD), belonging to four unrelated pedigrees, were born to consanguineous parents and 19 (11 IGHD and $8 \mathrm{CPHD})$ belonged to 14 families with at least two affected relatives (familial cases).

All the other 221 patients were sporadic with no apparent or declared consanguinity.

The patients were selected for the absence of cerebral tumors, cranial trauma, documented asphyxia, or other injuries at delivery. None of them carried causative mutations in other genes associated with pituitary dysfunctions (i.e. GH, GHRH-R, PIT1, PROP1, LHX3, and $L H X 4$; data not shown).

Patients or parents of patients under 18 years of age gave their written informed consent to participate in this study, which was approved by both the local Ethical Committee of our hospital and the other participating centers.

Italian normal-height subjects, matched for sex and age to the patients, were selected as controls.

\section{Endocrinological investigations}

Hormonal assays were performed using several commercial RIA kits, and normal values for each center were taken into account. The results of biochemical investigations at diagnosis were recorded including basal free thyroxine $\left(\mathrm{fT}_{4}\right)$, TSH, cortisol and ACTH levels, basal levels of GH, TSH, LH, FSH and cortisol, and their peaks in response to pituitary stimulation tests.

The patients were evaluated for serum GH level either after two consecutive classical provocative tests (with arginine or clonidine or insulin) or after one double stimulus with GHRH+arginine (23). Traditionally, a diagnosis of GHD is supported either by GH peaks $<10 \mathrm{ng} / \mathrm{ml}$ after both consecutive stimuli or by $\mathrm{GH}$ peaks $<20 \mathrm{ng} / \mathrm{ml}$ after the double provocative test.

A diagnosis of TSH deficiency was made if serum $\mathrm{T}_{4}$ concentration was under the normal level $\left(\mathrm{fT}_{4}<12.0-\right.$ $\mathrm{pmol} / \mathrm{l}$ ) or total $\mathrm{T}_{4}<65 \mathrm{nmol} / \mathrm{l}$ with a low serum TSH concentration $(<0.4 \mathrm{mIU} / \mathrm{l})$. ACTH deficiency was defined as morning serum cortisol of $<3.6 \mu \mathrm{g} / \mathrm{dl}$ $(100 \mathrm{nmol} / \mathrm{l})$. Gonadotroph axis was investigated only in patients of postpubertal age (i.e. over 15 years for 


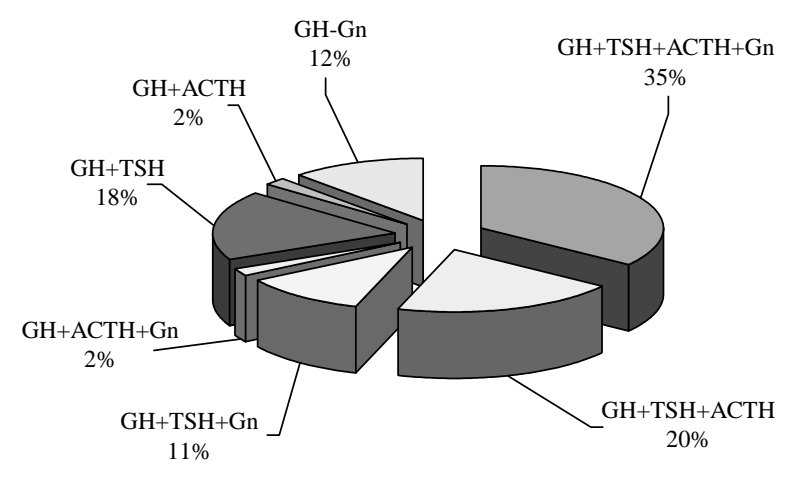

Figure 1 Pituitary hormone deficiencies repartition in CPHD patients.

female and 17 years for male patients). FSH-LH deficiency was diagnosed on the basis of delayed or absent pubertal development and no increase in serum FSH and LH in response to GnRH.

On the basis of hormonal deficiencies, the patients, including sporadic and familial cases, were classified as IGHD (156; 105 males and 51 females) and CPHD (88; 51 males and 37 females).

In Fig. 1, the pituitary hormone deficiency repartition in the CPHD patients is shown.

\section{Auxological evaluations}

The age and anthropometric data at diagnosis were available for 229 patients; of which 207 were sporadic (Table 1) and 22 had family history for IGHD/CPHD or were born to consanguineous parents (Table 2). Of the 244 patients, 215 (152 IGHD and 63 CPHD) were under 18 years of age, whereas a minority (4 IGHD and 25 CPHD) were adults. These adult patients either reported a childhood onset of the disorder or were diagnosed in the adult age but with a strong evidence of congenital hormonal pituitary deficiency.

For the remaining 15 patients $(6.1 \%$ of the total) for whom no data at the time of the first diagnosis was available, we obtained the clinical data only at their re-testing visit, and thus their data were not included in Tables 1 and 2 .

Table 1 Age and anthropometric data at diagnosis of IGHD and CPHD sporadic patients.

\begin{tabular}{lcc}
\hline & IGHD $(n=150)$ & CPHD $(n=57)$ \\
\hline Median age (years; min/max) & $9(0.3 / 21)$ & $7.3(0.1 / 19.9)$ \\
Mean height SDS \pm s.D. & $-2.6 \pm 0.791$ & $-3.36 \pm 1.78$ \\
(range) & $(-6 /-1.6)$ & $(-6.8 /-1.5)$ \\
Mean target ${ }^{\text {a }}$ corrected & $-2.095 \pm 0.698$ & $-2.89 \pm 1.07$ \\
height SDS \pm s.D. (range) $(-4.2 /-1.4)$ & $(-5.6 /-1.4)$ \\
Mean $\Delta$ bone age $^{\mathrm{b}} \pm$ S.D. & $-2.2 \pm 0.96$ & $-3.04 \pm 1.2$ \\
\hline
\end{tabular}

aTarget height calculated from the parents' stature.

'Difference between the chronological age and the bone age at diagnosis.

\section{Imaging investigations}

Morphological evaluation of the hypothalamus-pituitary area and/or the $\mathrm{CN}$ was performed by magnetic resonance imaging (MRI), using pre-contrast coronal spin-echo T1-weighted images followed by post-gadolinium T1-weighted imaging, in 143 out of 244 patients.

Abnormalities were found in 37 out of 65 IGHD (56.9\%) and in 69 out of 78 CPHD (88.5\%) patients. Ectopy of the neurohypophysis was observed in 11 out of 65 IGHD (16.9\%) and in 22 out of 78 CPHD (28.2\%) patients, whereas SOD was present only in two IGHD (3.08\%) and six CPHD (7.69\%) patients.

\section{Genetic analysis}

Genomic DNA was extracted from lymphocytes by the salting out procedure (24). The entire coding region of the HESX1 gene and intron-exon boundaries were amplified by PCR (conditions and primers are reported in Supplementary Materials, see section on supplementary data given at the end of this article).

Mutation detection and genotyping were carried out by denaturing HPLC (DHPLC) scanning on an automated HPLC instrument (Wave, Transgenomic, Santa Clara, CA, USA). As this method allows the identification of variations at the heterozygous state, all the amplicons were also mixed with a corresponding reference PCR product prior to the heteroduplex generation cycle, in order to detect mutations at the homozygous state. The temperature required for successful resolution of the heteroduplex molecules was determined using an online software (http:// insertion.stanford.edu/melt.html). The products were eluted from the column using a linear acetonitrile gradient at a constant flow rate of $1.5 \mathrm{ml} / \mathrm{min}$ (Supplementary Methods, see section on supplementary data given at the end of this article). Each fragment was analysed at the recommended temperature and at two degree over.

The PCR products displaying a heteroduplex peak were directly sequenced in both directions on an $\mathrm{ABI}$ 3100 automated sequencer, using the Big-dye terminator cycle sequencing reaction kit following the manufacturer's instructions (Applied Biosystem, Foster City, CA, USA).

\section{Cell cultures}

GH4C1 (ATCC, Manassas, VA, USA) and Chinese hamster ovary (CHO) cells were cultured in Ham's F10 (15\% heat-inactivated horse serum and 2.5\% heat-inactivated fetal bovine serum) and Ham's F12 media ( $10 \%$ heat-inactivated fetal bovine serum) (Sigma-Aldrich) respectively. Both the media were supplemented with $2 \mathrm{mM}$ L-glutamine, $100 \mathrm{U} / \mathrm{ml}$ penicillin, and $100 \mu \mathrm{g} / \mathrm{ml}$ streptomycin (Sigma-Aldrich). 
Table 2 Age and anthropometric data at diagnosis of IGHD and CPHD patients with family history of the disease or born to consanguineous parents.

\begin{tabular}{lcc}
\hline & IGHD $(n=13)$ & CPHD $(n=9)$ \\
\hline Median age (years; min/max) & $8.3(1.4 / 12.6)$ & $9.4(0.3 / 18.1)$ \\
Mean height SDS \pm S.D. & $-2.11 \pm 0.5$ & $-1.78 \pm 1.6$ \\
$\quad($ range $)$ & $(-7.2 /-1.4)$ & $(-4.4 /-0.1)$ \\
Mean target ${ }^{\text {a }}$ corrected & $-1.3 \pm 1.95$ & $-2.33 \pm 1.62$ \\
$\quad$ height SDS \pm s.D. (range) & $(-7.4 / 0.2)$ & $(-4.2 /-1.3)$ \\
Mean $\Delta$ bone age ${ }^{b} \pm$ S.D. & $-2.71 \pm 0.86$ & $-2.42 \pm 2.33$ \\
\hline
\end{tabular}

'Target height calculated from the parents' stature.

${ }^{b}$ Difference between the chronological age and the bone age at diagnosis

\section{Plasmid preparation and cell transfections}

A 2232 bp product encompassing the entire HESX1 gene was amplified from the patient heterozygous for the $c .357+3 G>A$ mutation with the following primers: 5'-GGATCCTGGGCAAGTGTTCATTGACATGCTA-3' (forward) and 5'-GATATCAGAATCCAGCTTGTGGAATCACTTAGTC-3' (reverse) located at $-180 \mathrm{bp}$ from the ATG translation initiation codon and at $318 \mathrm{bp}$ upstream of the stop codon within the $3^{\prime}$-UTR respectively. Both the primers contained a non-template restriction endonuclease recognition sequence at the $5^{\prime}$-end (underlined; BamHI in the forward and EcoRV in the reverse).

A proofreading Taq polymerase (Finnzymes, Espoo, Finland) was used with the following PCR cycle: $94{ }^{\circ} \mathrm{C}$ for $6 \mathrm{~min}$, followed by 25 cycles at $94{ }^{\circ} \mathrm{C}$ for $20 \mathrm{~s}$ and $62{ }^{\circ} \mathrm{C}$ for $4 \mathrm{~min}$.

To separate the wild-type and the mutant alleles, the PCR fragment obtained from the heterozygous patient was cloned into the pMOSBlue T-vector (pMOSBlue T-vector kit; Amersham). The clones were sequenced to check for polymerase-induced errors and digested with BamHI and EcoRV restriction enzymes. The digested products were run on a $1.5 \%$ agarose gel and purified by the QIAquick Gel extraction kit (Qiagen).

The purified fragments corresponding to the two different alleles were inserted into the pcDNA3.1 $(+)$ expression vector (Invitrogen), previously digested with the same endonucleases, following the manufacturer's instructions. DH101F' competent cells were then transformed with the two different constructs and grown on LB/ampicillin media, and the plasmid DNA was extracted by columns (JETSTAR 2.0 Maxi, Genomed, Löhne, Germany) and checked again by sequencing.

Plasmid DNA was used for transient transfection of the rat pituitary $\mathrm{GH} 4 \mathrm{C} 1$ and the $\mathrm{CHO}$ cell lines. Cells were grown to $\sim 80 \%$ confluence in $35 \mathrm{~mm}$ dishes and transfected with $1 \mu \mathrm{g}$ of each construct using the Fugene 6 Transfection Reagent (Roche Diagnostics), following the manufacturer's instructions.

To evaluate whether the alternative transcripts were subjected to nonsense-mediated mRNA decay (NMD), CHO cells transfected with the wild-type and mutated constructs were treated, $48 \mathrm{~h}$ after transfection, with $50 \mu \mathrm{g} / \mathrm{ml}$ of cycloheximide (CHX, Sigma-Aldrich), an inhibitor of protein synthesis, for $4 \mathrm{~h}$.

\section{Synthesis and amplification of HESX1 cDNA}

Total RNA was extracted from the GH4C1 cell line, transfected with the wild-type and mutant constructs, and from the fresh peripheral blood lymphocytes of two healthy controls by RNeasy Mini kit (Qiagen).

The cDNA obtained from the constructs was amplified by RT-PCR using the RETROscript kit (Ambion, Foster City, CA, USA) and the following two primers $5^{\prime}$ AACTGCAGGAAGATCCCAGCCCTA-3' (forward) and 5'-TTCCACTGATTCTTCATGCTCTGCAA-3'(reverse), located within exon 1 at $-83 \mathrm{bp}$ from the ATG translation initiation codon and at $+59 \mathrm{bp}$ with respect to the stop codon in the 3 '-UTR respectively.

The cDNA obtained from the lymphocytes was amplified using the following primers: 5'-AAGATCCCAGCCCTATACAC-3' (forward) and 5'-TCCAGCAGATTTGTGTTGAAA-3' (reverse), located at $-74 \mathrm{bp}$ from the ATG translation site and at c.554 within exon 4 respectively.

The PCR products were separated on a $2 \%$ agarose gel, excised from the gel and directly sequenced (ABI Prism 3100).

\section{RNA secondary structure analysis}

Secondary structures and the minimum optimal free energies for the HESX1 3'-UTR c. $558+48 \mathrm{G}$ and $3^{\prime}$-UTR c. $558+48$ A variants were predicted using the RNAfold online program (http://rna.tbi.univie.ac.at/).

Potential UTR functional regulatory elements were identified by means of the UTRScan program that looks for UTR functional elements by searching for the patterns collected in the UTRsite database (http:// itbtools.ba.itb.cnr.it/utrscan).

\section{Results}

\section{Genetic analysis of the HESX1 gene}

A total of 244 patients affected by IGHD or combined GHD were analysed for the presence of causal mutations in the HESX1 gene. The entire coding sequence and the intron-exon boundaries of the gene were screened by DHPLC analysis. A heteroduplex peak was displayed by nine samples suggesting the presence of a variation at the heterozygous state. Direct sequencing of these samples revealed five different nucleotide substitutions of which three were non-synonymous changes $(Q 6 H$, N125S, and V129I; Table 3). All the variations were searched in a panel of Italian control individuals ( $n=100-646)$ by DHPLC genotyping and subsequent sequencing to confirm the presence of the variant. 
Table 3 Genotype frequencies of HESX1 variations in patients and controls.

\begin{tabular}{|c|c|c|c|c|c|c|c|}
\hline $\begin{array}{l}\text { Nucleotide } \\
\text { change }^{\mathrm{a}}\end{array}$ & $\begin{array}{l}\text { Database } \\
\text { entry }^{b}\end{array}$ & Position & $\begin{array}{l}\text { Amino acid } \\
\text { change }\end{array}$ & Genotype & $\begin{array}{l}\text { IGHD sporadic } \\
\text { patients }(n(\%))\end{array}$ & $\begin{array}{l}\text { CPHD sporadic } \\
\text { patients }(n(\%))\end{array}$ & $\begin{array}{l}\text { Control sub- } \\
\text { jects }(n(\%))\end{array}$ \\
\hline c. $18 \mathrm{G}>\mathrm{C}$ & - & Exon 1 & Q6H & $\begin{array}{l}\mathrm{GG} \\
\mathrm{GC} \\
\mathrm{CC}\end{array}$ & $\begin{array}{l}143(100) \\
0 \\
0\end{array}$ & $\begin{array}{l}77(98.7) \\
1(1.3) \\
0\end{array}$ & $\begin{array}{l}116(100) \\
0 \\
0\end{array}$ \\
\hline c. $357+3 \mathrm{G}>\mathrm{A}$ & - & IVS2 & - & $\begin{array}{l}\mathrm{GG} \\
\mathrm{GA} \\
\mathrm{AA}\end{array}$ & $\begin{array}{l}142(99.3) \\
1(0.7) \\
0\end{array}$ & $\begin{array}{l}78(100) \\
0 \\
0\end{array}$ & $\begin{array}{l}646(100) \\
0 \\
0\end{array}$ \\
\hline c. $374 A>G$ & rs9878928 & Exon 3 & N125S & $\begin{array}{l}A A \\
A G \\
G G\end{array}$ & $\begin{array}{l}140(97.9) \\
3(2.1) \\
0\end{array}$ & $\begin{array}{l}78(100) \\
0 \\
0\end{array}$ & $\begin{array}{l}641(98.3) \\
5(1.7) \\
0\end{array}$ \\
\hline c. $385 \mathrm{G}>\mathrm{A}$ & - & Exon 3 & V129I & $\begin{array}{l}\text { GG } \\
\text { GA } \\
\text { AA }\end{array}$ & $\begin{array}{l}143(100) \\
0 \\
0\end{array}$ & $\begin{array}{l}76(97.4) \\
2(2.6) \\
0\end{array}$ & $\begin{array}{l}642(99.4) \\
4(0.6) \\
0\end{array}$ \\
\hline$c .558+48 \mathrm{G}>\mathrm{A}$ & - & $3^{\prime}$-UTR & - & $\begin{array}{l}\mathrm{GG} \\
\mathrm{GA} \\
\mathrm{AA}\end{array}$ & $\begin{array}{l}142(99.3) \\
1(0.7) \\
0\end{array}$ & $\begin{array}{l}78(100) \\
0 \\
0\end{array}$ & $\begin{array}{l}230(100) \\
0 \\
0\end{array}$ \\
\hline
\end{tabular}

${ }^{\mathrm{a}}$ The numbering is referred to the GenBank entries AF059734. Nucleotide numbering reflects cDNA numbering with 1 corresponding to the A of the ATG translation initiation codon in the reference sequence. The nucleotide number refers to the position in the coding sequence.

${ }^{b}$ http://www.ncbi.nlm.nih.gov.

Only the non-synonymous N125S was already present in the public database (http://www.mcbi.nlm.nih.gov/). The N125S and V129I substitutions were detected at comparable frequency in patients and controls (Table 3).

The CPHD patient carrying the $Q 6 H$ mutation, which was not present in 116 controls, was a pre-pubertal child who progressively developed multiple hypopituitarism, first GH and, afterwards, TSH and ACTH deficiencies, in a plurimalformative syndrome characterized by short stature and anatomical malformations not associated with SOD phenotype. The same mutation had previously been reported in a CPHD patient with mild pituitary dysfunction and no midline brain defect and in none of the 100 controls analysed by the authors (14). As this patient and the mutation have previously been described by us (25), the case will not be further discussed.

The other two variations, in the $3^{\prime}$-UTR (c. $558+48$ $\mathrm{G}>\mathrm{A}$ ) and in IVS2 (c.357+3G>A), were identified in two distinct patients for the first time in this study and in none out of 230 and 646 healthy controls respectively.

To assess whether the variation $3^{\prime}$-UTR c.558+48 $\mathrm{G}>\mathrm{A}$ could affect the predicted mRNA stability and secondary structure, we performed an in silico analysis with the RNAfold online program (http://rna.tbi.univie. ac.at/). The secondary structure analysis indicated that the $3^{\prime}$-UTR alleles generate two secondary structures with similar minimum free energy (dG) values (Fig. 2). To determine whether the $3^{\prime}$-UTR variants contained regulatory elements with different properties, a bioinformatics analysis of the HESX1 3'-UTR was performed by using the UTRScan program (http://itbtools.ba.itb.cnr. it/utrscan). Both the alleles displayed the same specific sequence binding sites for the different factors predicted by the software. It is thus likely that the variation detected in one patient in the $3^{\prime}$-UTR does not affect the
mRNA stability and regulation, and that it represents a rare benign variant.

The c. $357+3 \mathrm{G}>\mathrm{A}$ variation is located immediately downstream the highly conserved dinucleotide GT at the donor splice site of intron 2. As changes at this position have frequently been found associated to perturbation of the correct splicing, leading to pathological conditions (26), we investigated the influence of c. $357+3 \mathrm{G}>\mathrm{A}$ on the HESX1 mRNA maturation.

\section{Consequence of the c.357+3G $>A$ variation on the mRNA processing}

Investigation of the strength of the IVS2 donor site using a splice site prediction program (http://www.frsuitfly. org/seq_tools/splice.html) showed that the wild-type

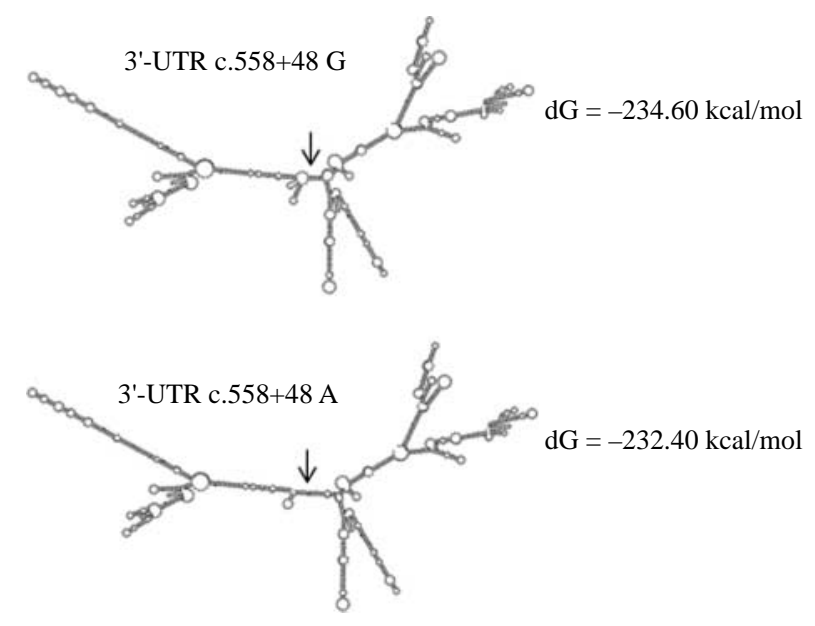

Figure 2 Representation of the human HESX1 3'-UTR variant secondary structures as predicted by the RNAfold online software (http://rna.tbi.univie.ac.at/). The minimum free energy decrease is indicated. The arrows indicate the position of the variant nucleotide. 
c. $357+3 G$ allele confers a score of $0.84(\max =1)$ to the splice site, and that the $c .357+3 A$ allele increases this score to 0.93 .

To test whether the increase in the strength of this donor splice site could have a functional consequence, as the mRNA of the patient was not available, we performed an in vitro splicing assay by means of expression constructs. GH4C1 cells were transfected with the plasmid bearing the wild-type and the mutant HESX1 alleles. The mRNA was extracted and submitted to RT-PCR with primers flanking the entire HESX1 coding sequence. After gel electrophoresis, the wild-type HESX1 yielded three splicing forms (Fig. 3a, lane 2). Sequencing of the three bands extracted from the agarose revealed that these corresponded to the whole cDNA of $700 \mathrm{bp}$, to a product of $500 \mathrm{bp}$ with the skipping of exon 2, and to a 398 bp cDNA missing exons 2 and 3 respectively. This is the first evidence of the presence of different splicing isoforms generated by the wild-type HESX1 allele. Notably, the plasmid with the mutant HESX1 yielded only two splicing products corresponding to the whole cDNA (700 bp) and to the skipping of exons 2-3 (398 bp; Fig. 3a, lane 1). The mRNA lacking exon 2 was absent in the mutant. The same results were obtained by transfecting the $\mathrm{CHO}$ cell line with both the wild-type and the mutant constructs (Fig. 4, lane 1 and 3).

To test whether the three splicing isoforms, produced by the plasmid bearing the wild-type HESX1, were normally present in healthy individuals or represented an artifact of our in vitro experimental conditions, we searched for the HESX1 ectopic transcripts in the lymphocytes extracted from two subjects of the control group. The three splicing products detected in the wildtype construct were also present in the lymphocytes of these two subjects (Fig. 3b), confirming that these

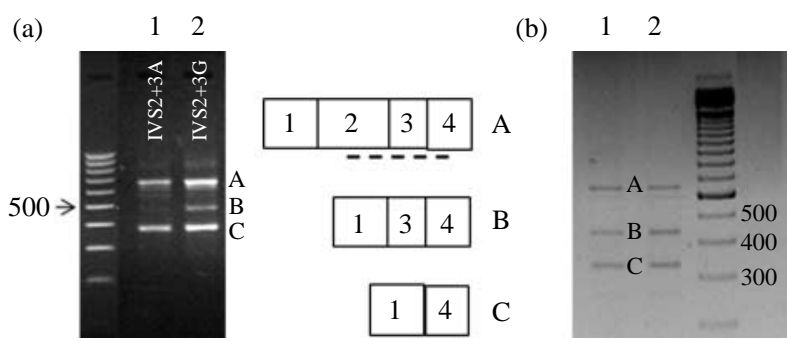

Figure 3 (a) HESX1 mRNA from GH4C1 cells transiently transfected with the $c .357+3 A$ mutant allele (lane 1 ) and the wildtype allele (lane 2). (A) 700 full-length transcript; (B) 500 bp isoform skipping exon 2; (C) $398 \mathrm{bp}$ isoform skipping exons 2-3. The scheme of the three isoforms is reported, where the homeodomain is depicted by a dotted line. (b) HESX1 mRNA extracted from lymphocyte of two healthy normal-height subjects. (A) $628 \mathrm{bp}$ full-length transcript; (B) 428 bp isoform skipping exon 2; (C) 326 bp isoform missing exons $2-3$. The size of the corresponding transcripts in (a) and (b) are different since the RT-PCR was performed with different couples of primers on the mRNA from $\mathrm{GH} 4 \mathrm{C} 1$ cells and on the mRNA from lymphocytes (see Materials and methods). All the visible bands were extracted from the gel and sequenced.

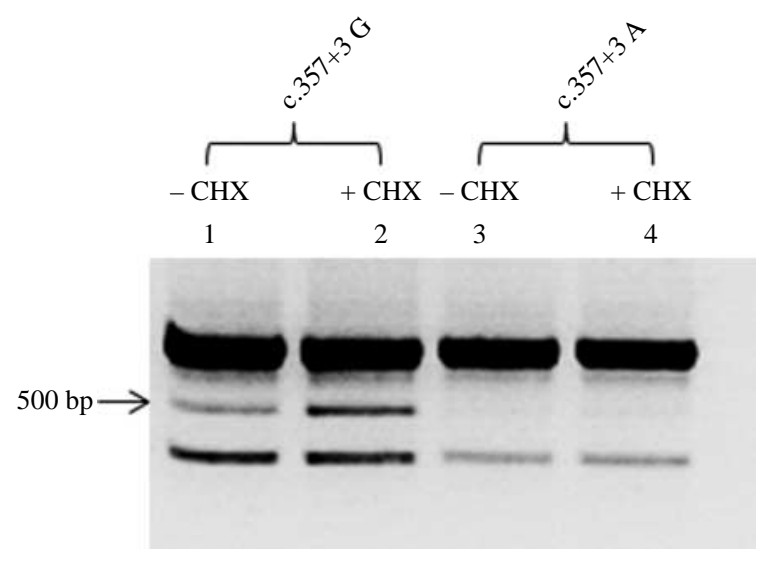

Figure 4 HESX1 mRNA from $\mathrm{CHO}$ cells transiently transfected with the wild-type (lanes 1 and 2) and mutant (lanes 3 and 4) HESX1 alleles, treated (lanes 2 and 4) and not treated (lane1 and 3) with $\mathrm{CHX}$. The transcript level was normalized to that of glyceraldehyde3-phosphate dehydrogenase (GAPDH) RNA using the Quantity One software (Bio-Rad).

represent normal isoforms of the HESX1 mRNA and not an artifact of the in vitro experiments.

Both the skipping of exon 2 and exons 2-3 alter the open reading frame of the transcripts, and if translated, they would lead to prematurely truncated proteins at residues 53 (within exon 3) and 66 (within exon 4) respectively. These two hypothetical truncated proteins lack the functional HD involved in the DNA binding and all the following residues.

We hypothesized that the isoform deleted of exon 2 (which is not generated by the mutant allele) is subjected to NMD, a surveillance mechanism of the protein synthesis that rapidly degrades mRNAs when a premature stop codon is present more than 50-55 nucleotides upstream the $3^{\prime}$-most exon-exon junction (27). To demonstrate this hypothesis, the CHO cells, transfected with the HESX1 gene-bearing plasmids (wild-type and mutant, the latter was used as a negative control), were treated with $\mathrm{CHX}$, an inhibitor of the protein synthesis and consequently of the NMD machinery. As shown in Fig. 4, the CHX exposure increases the expression level of the isoform lacking exon 2 in the wild-type allele (lane 2) of about $40 \%$ (with a normalized ratio of 0.78 for the treated and 0.54 for the non-treated cells) demonstrating that this isoform is degraded when the mRNA is translated. The other two bands did not show any visible change after the CHX exposure. No band corresponding to the isoform missing exon 2 was detected in the mutant, even after treatment with $\mathrm{CHX}$.

\section{Clinical features of patient bearing the c. $357+3 G>$ A mutation}

The patient carrying the $c .357+3 G>A$ mutation was a boy born at term by spontaneous vaginal delivery. 
At birth, his weight was $2800 \mathrm{~g}$. There were no signs of hypoglycemia or respiratory distress during the neonatal period or congenital hypothyroidism, and his psychomotor development was normal. At the age of 12.6 years, he showed growth retardation, with a height of $130.7 \mathrm{~cm}(-2.9$ SDS), a weight of $25.9 \mathrm{~kg}$ $(-3$ SDS), and bone age of $8.10(\Delta=-3.5)$. His father and mother had a height of 166 and $146 \mathrm{~cm}$ respectively (target height: $163.5 \mathrm{~cm}$ ). Suspecting GHD, a GH secretion test was performed in this boy revealing GHD (ITT: peak $4.7 \mathrm{ng} / \mathrm{ml}$; clonidine stimulation: peak $0.6 \mathrm{ng} / \mathrm{ml})$. The rest of the endocrinology was normal (TSH $3 \mu \mathrm{U} / \mathrm{ml}$; free tri-iodothyronine $3.6 \mathrm{pg} / \mathrm{ml}$ and $\mathrm{fT}_{4} 15.7 \mathrm{pg} / \mathrm{ml}$ ). The peaks of TSH and PRL in response to TRH were normal. MRI of the brain and pituitary did not reveal any abnormality. At the age of 12.8 years, he started the therapy with recombinant GH. After 6 months, at the age of 13.2 years, his height was $135.6 \mathrm{~cm}$ ( -2.6 SDS), bone age was 9.9 $(\Delta=-3.3)$, and weight was $30 \mathrm{~kg}(-2.4$ SDS $)$. At the last follow-up visit, he was 13.9 years old, and he reached the height of $138.1 \mathrm{~cm}(-2.8$ SDS $)$ with a bone age of $10.3(\Delta=-3.6)$ and a weight of $31.4 \mathrm{~kg}(-2.4)$.

\section{Discussion}

Mutations in the HEXS1 gene represent a rare cause of congenital GHD associated with a wide spectrum of neuroradiological features, such as SOD, hypoplastic or normal anterior pituitary, disrupted or normal pituitary stalk, ectopic or normally located posterior pituitary, and anterior aplasia.

We screened the HESX1 gene in 244 Italian patients with a broad spectrum of congenital pituitary defects ranging in severity from IGHD to SOD with panhypopituitarism. Two deleterious mutations were identified in two patients: a novel variation at the third base of the IVS2 (c. $357+3 \mathrm{G}>\mathrm{A}$ ) and the variation $\mathrm{Q} 6 \mathrm{H}$, previously reported by us (25), accounting for $0.8 \%$ of the total patients. These data are in agreement with other studies $(3,14,21,22)$ and confirm the low frequency of HESX1 mutations in hypopituitarism.

The case described in this study, heterozygous for c. $357+3 \mathrm{G}>\mathrm{A}$, is affected by an isolated pituitary dysfunction. Unfortunately, the parents of the patient were not available to test whether the variation was inherited or whether it was a de novo mutation. In any case, if the mutation was inherited, the incomplete penetrance associated with a relatively mild phenotype would be consistent with the mild disease and the reduced penetrance observed in heterozygous Hes $x 1$ neonate mice (3) and reported in other heterozygous patients (14).

We demonstrated that c. $357+3 \mathrm{G}>\mathrm{A}$ alters the HESX1 alternative splicing by preventing the generation of an alternatively spliced isoform. Two HESX1 mutations have previously been reported that interfered with the mRNA processing: an Alu insertion in exon 3 causing the skipping of this exon (19) and the point mutation at position +2 of intron $2(c .357+2 T>C)$ within the almost invariant dinucleotide of the donor splice site (20) generating two isoforms lacking exon 3 and exons 2-3. Both the mutations abolished the synthesis of the full-length wild-type mRNA in the homozygous patients. The authors explained the presence of additional isoforms in the patients as a result of aberrant splicing consequent to the mutations. However, we detected one of these alternative isoforms (lacking exons 2-3) and a novel isoform (lacking exon 2) in two different cell types (Fig. 3a) transformed with the wild-type construct and in the mRNA extracted from the lymphocytes of two healthy individuals (Fig. 3b).

Referring to the presence of alternative mRNA in normal subjects, a possible explanation to the discordant findings between our data and those obtained by the other authors $(19,20)$ might be the different sources of the RNA used for the RT-PCR. We extracted the mRNA from peripheral blood of the control subjects, whereas Sobrier et al. $(19,20)$ extracted the mRNA from Epstein-Barr virus (EBV)-transformed lymphocytes of healthy donor individuals. It is plausible that the ectopic transcription in the lymphocytes of healthy individuals better reflects the scenario of the healthy developing pituitary gland with respect to the transcription in EBV-transformed lymphocytes.

The insertion of an Alu sequence and the mutation of the consensus dinucleotide at the donor splice site $(19,20)$ represent destructive mutations that completely prevent the synthesis of the full-length cDNA, but at the same time they might favor alternative isoforms normally produced at a lower dose. In the case of the $c .357+2 T>C$ mutation reported by Sobrier (20), it might be possible that this isoform became evident only when the synthesis of wild-type mRNA was completely abolished in the patient's EBV-transformed lymphocytes, and that this isoform was not visible in the control-transformed lymphocytes $(19,20)$.

Conversely, the c.357+3G>A mutation, increasing the strength of the IVS2 donor splice site, might favor the formation of the full-length cDNA and weaken the generation of the alternatively isoform missing exon 2 that was no longer detectable in the mRNA generated by the mutant construct.

Both the HESX1 isoforms lacking exon 2 and exons 2-3 contain a premature termination codon at residues 53 (within exon 3 of the full transcript) and 66 (within the last exon, namely exon 4) respectively. We demonstrated that the isoform deleted of exon 2 (which is not produced by the mutant allele) is degraded by the NMD pathway by showing that its level increases when the protein synthesis is blocked by the CHX treatment (Fig. 4).

The coupling of alternative splicing and NMD is a recently described mechanism of downregulation of 
gene expression that allows the use of the intrinsic alternative splicing machinery to physiologically regulate the expression of a wide variety of genes in a developmental stage and cell-specific manner in many organisms from yeast to humans $(27,28)$. It seems that at least $10-15 \%$ of the human transcripts can be switched off by NMD coupled to alternative splicing (27). It can be speculated that a diminished downregulation of HESX1 at a critical stage during early development might lead to an increased repression of HESX1 target genes such as PROP1 and to an inappropriate differentiation of forebrain and pituitary primordia. Thus, contrarily to the other splicing mutations identified so far in the HESX1 gene that abolished the usage of the IVS2 splice site and led to the absence of the wild-type protein, the $c .357+3 G>A$ mutation might have a dominant negative effect on the regulation of HESX1 expression by increasing the HESX1-repressive effect.

The identification of the splicing mutation c.357 $+3 G>A$ opens new insight into the mechanism of HESX1 regulation. Alternative splicing leading to NMD might be one of the mechanisms that regulate the correct spatial and temporal patterns of the HESX1 gene expression. In our patient, the absence of one of the factors that contributes to negatively regulate the expression of HESX1, which acts as a repressor of several pituitary genes, might lead to an impaired pituitary function resulting in IGHD.

\section{Supplementary data}

This is linked to the online version of the paper at http://dx.doi.org/10. 1530/EJE-11-0047.

\section{Declaration of interest}

The authors declare that there is no conflict of interest that could be perceived as prejudicing the impartiality of the research reported.

\section{Funding}

This work was supported by Eastern Piedmont University, by Regione Piemonte (Ricerca Sanitaria Finalizzata 2008bis), and by Cariplo Foundation.

\section{Acknowledgements}

We are grateful to all the patients and their families.

\section{References}

1 Dasen JS \& Rosenfeld MG. Signaling mechanisms in pituitary morphogenesis and cell fate determination. Current Opinion in Cell Biology 19996 669-677. (doi:10.1016/S0955-0674(99) 00034-4)

2 Dasen JS \& Rosenfeld MG. Signaling and transcriptional mechanisms in pituitary development. Annual Review of Neuroscience 2001 24 327-355. (doi:10.1146/annurev.neuro.24.1.327)
3 Dattani MT, Martinez-Barbera JP, Thomas PQ, Brickman JM, Gupta R, Mårtensson IL, Toresson $H$, Fox $M$, Wales JK, Hindmarsh PC, Krauss S, Beddington RS \& Robinson IC. Mutations in the homeobox gene HESX1/Hesx1 associated with septo-optic dysplasia in human and mouse. Nature Genetics 1998 19 125-133. (doi:10.1038/477)

4 Kelberman D \& Dattani MT. Hypothalamic and pituitary development: novel insights into the aetiology. European Journal of Endocrinology 2007157 S3-S14. (doi:10.1530/EJE07-0156)

5 Gage PJ, Brinkmeier ML, Scarlett LM, Knapp LT, Camper SA \& Mahon KA. The Ames dwarf gene, df, is required early in pituitary ontogeny for the extinction of Rpx transcription and initiation of lineage-specific cell proliferation. Molecular Endocrinology 199610 1570-1581. (doi:10.1210/me.10.12.1570)

6 Treier M, Gleiberman AS, O'Connell SM, Szeto DP, McMahon JA, McMahon AP \& Rosenfeld MG. Multistep signaling requirements for pituitary organogenesis in vivo. Genes and Development 199812 1691-1704. (doi:10.1101/gad.12.11.1691)

7 Kazanskaya OV, Severtzova EA, Barth KA, Ermakova GV, Lukyanov SA, Benyumov AO, Pannese M, Boncinelli E, Wilson SW \& Zaraisky AG. Anf: a novel class of vertebrate homeobox genes expressed at the anterior end of the main embryonic axis. Gene 1997200 25-34. (doi:10.1016/S03781119(97)00326-0)

8 Thomas PQ, Johnson BV, Rathjen J \& Rathjen PD. Sequence, genomic organization, and expression of the novel homeobox gene Hesx1. Journal of Biological Chemistry 1995270 3869-3875. (doi:10.1074/jbc.270.8.3869)

9 Dasen JS, Barbera JP, Herman TS, Connell SO, Olson L, Ju B, Tollkuhn J, Baek SH, Rose DW \& Rosenfeld MG. Temporal regulation of a paired-like homeodomain repressor/TLE corepressor complex and a related activator is required for pituitary organogenesis. Genes and Development 200115 3193-3207. (doi:10.1101/gad.932601)

10 Hermesz E, MacKem S \& Mahon KA. Rpx: a novel anteriorrestricted homeobox gene progressively activated in the prechordal plate, anterior neural plate and Rathke's pouch of the mouse embryo. Development 1996122 41-52.

11 Carvalho LR, Woods KS, Mendonca BB, Marcal N, Zamparini AL, Stifani S, Brickman JM, Arnhold IJ \& Dattani MT. A homozygous mutation in HESX1 is associated with evolving hypopituitarism due to impaired repressor-corepressor interaction. Journal of Clinical Investigation $2003 \mathbf{1 1 2}$ 1192-1201. (doi:10.1172/ JCI18589)

12 Martinez-Barbera IP, Rodriguez TA \& Beddington RS. The homeobox gene Hesx 1 is required in the anterior neural ectoderm for normal forebrain formation. Developmental Biology 2000223 422-430. (doi:10.1006/dbio.2000.9757)

13 Dattani MT \& Robinson IC. HESX1 and septo-optic dysplasia. Reviews in Endocrine and Metabolic Disorders 20033 289-300. (doi:10.1023/A:1020945406356)

14 Thomas PQ, Dattani MT, Brickman JM, McNay D, Warne G, Zacharin M, Cameron F, Hurst J, Woods K, Dunger D, Stanhope R, Forrest S, Robinson IC \& Beddington RS. Heterozygous HESX1 mutations associated with isolated congenital pituitary hypoplasia and septo-optic dysplasia. Human Molecular Genetics 200110 39-45. (doi:10.1093/hmg/10.1.39)

15 Wales JKH \& Quarrell OWJ. Evidence for possible Mendelian inheritance of septo-optic dysplasia. Acta Paediatrica $1996 \mathbf{8 5}$ 391-392. (doi:10.1111/j.1651-2227.1996.tb14044.x)

16 Brickman JM, Clements M, Tyrell R, McNay D, Woods K, Warner J, Stewart A, Beddington RS \& Dattani M. Molecular effects of novel mutations in Hesx1/HESX1 associated with human pituitary disorders. Development $2001 \mathbf{1 2 8} 5189-5199$.

17 Tajima T, Hattorri T, Nakajima T, Okuhara K, Sato K, Abe S, Nakae J \& Fujieda K. Sporadic heterozygous frameshift mutation of HESX1 causing pituitary and optic nerve hypoplasia and combined pituitary hormone deficiency in a Japanese patient. Journal of Clinical Endocrinology and Metabolism 200388 45-50. (doi:10.1210/jc.2002-020818) 
18 Cohen RN, Cohen LE, Botero D, Yu C, Sagar A, Jurkiewicz M \& Radovick S. Enhanced repression by HESX1 as a cause of hypopituitarism and septooptic dysplasia. Journal of Clinical Endocrinology and Metabolism $2003 \mathbf{8 8}$ 4832-4839. (doi:10. 1210/jc.2002-021868)

19 Sobrier ML, Netchine I, Heinrichs C, Thibaud N, Vié-Luton MP, Van Vliet G \& Amselem S. Alu-element insertion in the homeodomain of HESX1 and aplasia of the anterior pituitary. Human Mutation 200525 503. (doi:10.1002/humu.9332)

20 Sobrier ML, Maghnie M, Vié-Luton MP, Secco A, di Iorgi N, Lorini R \& Amselem S. Novel HESX1 mutations associated with a life-threatening neonatal phenotype, pituitary aplasia, but normally located posterior pituitary and no optic nerve abnormalities. Journal of Clinical Endocrinology and Metabolism 200691 4528-4536. (doi:10.1210/jc.2006-0426)

21 McNay DE, Turton JP, Kelberman D, Woods KS, Brauner R, Papadimitriou A, Keller E, Keller A, Haufs N, Krude H, Shalet SM \& Dattani MT. HESX1 mutations are an uncommon cause of septooptic dysplasia and hypopituitarism. Journal of Clinical Endocrinology and Metabolism 200792 691-697. (doi:10.1210/ jc.2006-1609)

22 Coya R, Vela A, Pérez de Nanclares G, Rica I, Castaño L, Busturia MA \& Martul P; GEDPIT group. Panhypopituitarism: genetic versus acquired etiological factors. Journal of Pediatric Endocrinology and Metabolism 200720 27-36.

23 Ghigo E, Bellone J, Aimaretti G, Bellone S, Loche S, Cappa M, Bartolotta E, Dammaco F \& Camanni F. Reliability of provocative tests toasses growth hormone secretory status. Study in 472 normally growing children. Journal of Clinical Endocrinology and Metabolism 1996 81 3323-3327. (doi:10.1210/jc.81.9.3323)

24 Miller SA, Dykes DD \& Polesky HF. A simple salting-out procedure for extracting DNA from human nucleated cells. Nucleic Acids Research 198816 1215. (doi:10.1093/nar/16.3.1215)

25 Corneli G, Vivenza D, Prodam F, Di Dio G, Vottero A, Rapa A, Bellone S, Bernasconi S \& Bona G. Heterozygous mutation of HESX1 causing hypopituitarism and multiple anatomical malformations without features of septo-optic dysplasia. Journal of Endocrinological Investigation 200831 689-693.

26 Krawczak M, Thomas NS, Hundrieser B, Mort M, Wittig M, Hampe J \& Cooper DN. Single base-pair substitutions in exonintron junctions of human genes: nature, distribution, and consequences for mRNA splicing. Human Mutation $2007 \mathbf{2 8}$ 150-158. (doi:10.1002/humu.20400)

27 Lewis B, Green R \& Brenner S. Evidence for the widespread coupling of alternative splicing and nonsense-mediated mRNA decay in humans. PNAS 2003100 189-192. (doi:10.1073/pnas. $0136770100)$

28 Lareau L, Brooks A, Soergel D, Meng Q \& Brenner S. The coupling of alternative splicing and nonsense-mediated mRNA decay. Advances in Experimental Medicine and Biology 2007623 190-211.

Received 18 January 2011

Accepted 16 February 2011 